\title{
Thermodynamics of Irreversible Process, Computerized Animated Visualization for Multi Component Mass Transport Sorption Problems in Nanocomposites
}

\author{
Anatoliy Kalinitchev* \\ Institute for Phys. Chem. \& Electro Chem, Russia Academia of Science, Russia

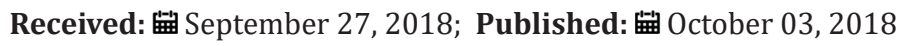 \\ *Corresponding author: Anatoliy Kalinitchev, Institute for Phys. Chem. \& ElectroChem, Rus. Academia of Science, GSP, Leninsky \\ Prospect, Moscow, Russia
}

Keywords: Nanocomposites (NC); NP-Nano-Sites; Waves Interaction; Selectivity; Peculiar Waves; Bi- Functionality; NC Models

\section{Mini Review}

There is presented the author's mini Review of the realized theoretical investigation of the Multi $(n=6)$-component Mass Transfer (MMT) kinetics of the process inside the modern combined sorption "Nano-Composite" (NC) materials. The visual NC examples considered in the author's manuscripts may be represented by the selective bi-functional $\mathrm{NC}$ as the "Metal"-Ion Exchangers (IEx)" planar NC L-membrane matrix where the inner active zero charged "NP ${ }^{0}$-nano-sites" (i.e. Nano Particles, $\mathrm{Me}^{0}$-agglomerates) are imbedded into the final combined NC-IEx sorption matrix resulting after the preliminary synthesis of the final NC L-matrix considered. The computer simulation for the modelling of the MMT NC kinetics is based here on the foundations of the irreversible thermodynamics such as multi(n)-component mass balance $\mathrm{n}$ (6)-Eqns. in partial differentials characterized fundamentally by the ${ }^{n e w} \mathrm{k}^{(2)}(6)$ - "thermodynamic variance" (k-parameter). The $\mathrm{k}^{(2)}$ "variance parameter" describes the well kown thermodynamic "degree of freedom" of the multi( $(n=6)$-component MMT NC kinetic system considered. The another fundamental characteristics of the irreversible thermodynamics are also included, namely the key wave concept $(W)$ of the propagating mode of the multi $(n=6)$-component $\left\{\mathrm{X}_{\mathrm{n}}(\mathrm{L}, \mathrm{T})\right\}$-concentration $\quad$ waves-distributions $\quad(\mathrm{n}=1,2, . .6) ; \quad$ Mass Action Laws $\left(\mathrm{MAL}_{\mathrm{S}}\right)$; "sink-source" mass transformation selective mechanism during the MMT NC kinetic process; the fundamental Nernst-Plank flux equations, electro-neutrality relations and some others.

The theoretical computer simulation is based on the two various bi-functional $\mathrm{k}^{(1,2)}$-NC Models elaborated for MMT NC kinetics previously $\left({ }^{\text {prev }} \mathrm{k}^{(1)}=5\right)$, and in this manuscript $\left({ }^{\text {new }} \mathrm{k}^{(2)}=6\right)$. The computer simulation based on the expanded ${ }^{n e w} k^{(2)}(6)$ NC Model here brings the final results: the propagating mode of the multi $(n=6)$-component $\left\{\mathrm{X}_{\mathrm{n}}(\mathrm{L}, \mathrm{T})\right\}$-concentration wavesdistributions in the NC L-membrane. The multi-component $(n=6)$ $\left\{\mathrm{X}_{\mathrm{n}}(\mathrm{L}, \mathrm{T})\right.$-concentration waves describe the MMT NC kinetics on the basis of the fundamental wave (W)-concept mentioned.

The $\mathrm{n}(6)$-components of the $\left\{\mathrm{X}_{\mathrm{n}}\right\}$-concentration composition $\left(\mathrm{n}={ }_{1,2}\left(\mathrm{R}^{0} \mathrm{p}\right)^{+} ;{ }_{(3,4)} \mathrm{p}^{+} ; \mathrm{j}_{5}{ }_{5}{ }_{6} \mathrm{R}^{0}\right)$ are participants of the MMT NC kinetics inside the bi-functional NC planar L-matrix with the two coexisting $\left(\mathrm{I}_{1,2} \& \mathrm{II}-\mathrm{MMT}\right.$ routes), and put together the MMT ${ }^{\mathrm{new}} \mathrm{k}^{(2)}(6)$ NC Model elaborated. The expanded MMT NC system considered with the new bi-functional ${ }^{n e w} \mathrm{k}^{(2)}(6)-\mathrm{NC}$ Model comprises the four $\left\{{ }_{3,4} \mathrm{p}^{\mathrm{X}}{ }_{\mathrm{m} 1,2}\left(\mathrm{R}^{0} \mathrm{p}\right)\right\}=\left\{2_{\mathrm{p}}{ }^{\mathrm{x}}{ }_{\mathrm{m}}\right\}$-principal paired components-participants, namely the two diffusing ${ }_{(3,4)} \mathrm{p}^{+}$-sorbate ions-principals $\left(\mathrm{D}_{3,4}>0\right)$ together with the corresponding fixed $m_{1,2}$-principals $\left(D_{1^{\prime} 2}=0\right)$ participated in the sorption(Ia-)-desorption(Id-)stages of the $\left(\mathrm{I}_{1,2}\right)$-selective $\mathrm{MAL}_{\mathrm{S}}$ reactions. The details of the MMT bi-functional $\left(\mathrm{I}_{1,2}\right.$-Selectivity \& Diffusivity, II) ${ }^{\text {new }} \mathrm{K}^{(2)}$-NC Model are illustrated via the conceptual visual diagrams in the full author's publications [SM\&EI J. v.2,N4, 2018 pp.128-132; MAMS J. 2019, in preparation]. The availability of the five $\left\{\mathrm{m}_{1,2} ;{ }_{(3,4)} \mathrm{p} ;{ }_{6} \mathrm{R}^{0}\right\}$-principal components namely, the four paired $\left\{2_{\mathrm{p}}{ }^{\mathrm{x}} \mathrm{z}_{\mathrm{m}}\right\}$-principals including the last introduced and crucial $\left(\mathrm{k}_{\mathrm{k}=6} \mathrm{R}^{0}\right)$-principal $6^{\text {th }}$-component which is fundamentally important for the investigation of the interference of the peculiar $\left\{\mathrm{X}_{1,2,6}(\mathrm{~L}, \mathrm{~T})\right\}$-travelling concentration waves calculated during the computer simulation elaborated. The key fundamental principal component $\left({ }_{6} \mathrm{R}^{0}\right)$ denotes the ${ }_{6} \mathrm{R}^{0}$ - "NP0 -nanosites" with 
the various $\left[{ }_{6} \mathrm{R}^{0}\right]$-concentrations of the "NP0-nanosites" (see above). The cardinal, fixed ${ }_{6} \mathrm{R}^{0}$-principal in the NC L-membrane is introduced purposely into the theoretical MMT NC kinetic system consideration in the full version of the author's manuscript [MAMS J., in preparation]. In addition to the $\left(\mathrm{I}_{1,2}\right)$-MMT selective route in the NC matrix it is included into consideration the second, $\left\{D_{3}\right.$ $\left.{ }_{5}\right\}$-multi-Diffusion (II)-MMT co-route for the two diffusing ${ }_{(3,4)} \mathrm{p}^{+}$ sorbate principals with taking into account the diffusing $\left(\mathrm{D}_{5}>0\right)$ $5^{\text {th }}$-co-ions $\left(\mathrm{j}_{5}\right)$. The $\mathrm{j}_{5}$-co-ionic component maintains the electroneutrality in the bi-functional combined MMT NC system namely, $\left(\mathrm{I}_{1,2}\right)$-selective sorption (for sorbed $\left.\mathrm{m}_{1,2}\right) \&(\mathrm{II})-\left\{\mathrm{D}_{3-5}\right\}$-multi-Diffusion (for ${ }_{(3,4)} \mathrm{p}^{+}, \mathrm{j}_{5}^{-}$-components, $\mathrm{D}_{3-5}>0$ ) described in the full version of the author's manuscripts [MS\&EI ; MAMS J.,in preparation]. The interference of the peculiar $\left\{\mathrm{X}_{1,2,6}(\mathrm{~L}, \mathrm{~T})\right\}$-travelling concentration waves during the computer simulation brings the chromatographic Displacement Development (DD)-behavior of the two interfering $\mathrm{X}_{1}(\mathrm{~L}, \mathrm{~T})$-displacer, and $\mathrm{X}_{2}(\mathrm{~L}, \mathrm{~T})$-displaced concentration waves [MS\&EI J. 2].For the MMT NC kinetics there is displayed visually (via the multi-colored "captured video", illustrated in the full versions [MS\&EI J. v.2(4) 2018; MAMS J., in preparation, 2019] that the reason for the atypical and peculiar $\left\{\mathrm{X}_{1,2,6}(\mathrm{~L}, \mathrm{~T})\right\}$-concentration waves behavior consists in the combined property expressed by the bi-functionality of the NC matrix via the combination of the (selectivity, $\mathrm{I}_{1,2}$ ) \& (II, Diffusivity)-MMT co-routes considered. The influence of the two principal ${ }_{(3,4)} \mathrm{p}^{+}$-sorbate participants-diffusants properties (with $\mathrm{D}_{3,4}>0$-mobility) is transferred to the peculiar $\mathrm{X}_{\mathrm{m}(1,2)}$
$(\mathrm{L}, \mathrm{T})$-concentration waves for the in-diffusible ${ }_{\mathrm{m}(1,2)}(\mathrm{Rp})^{+}$-principal components-complexes (where $\mathrm{D}_{1,2}=0$ ). The several illustrations and References for the given mini-Review including the structure of the NC bi-functional matrices; the various ( peculiar $_{1,2,6}$ and diffusing $_{3,4}$ ) multi(n)-components $\left\{\mathrm{X}_{\mathrm{n}}(\mathrm{L}, \mathrm{T})\right\}$-principal concentration waves, and finally "pictures-frames" of the travelling $\left\{\mathrm{X}_{\mathrm{n}}(\mathrm{L}, \mathrm{T})\right\}$-concentration waves are presented in the author's manuscripts mentioned above.

\section{Conclusion}

a) Computer simulation by the mass balance $n(6)$-Eqns. for a number of variants includes the contemporary and bifunctional Nano-Composite, $\mathrm{k}^{(2)}(6)-\mathrm{NC}$ Models elaborated.

b) Numerical results of the computerized modeling bring the interference of the multi-n(6)-component $\left\{\mathrm{X}_{\mathrm{n}}(\mathrm{L}, \mathrm{T})\right\}$ - travelling concentration waves in the $\mathrm{NC}$ planar L-membrane.

c) Phenomenological wave $\mathrm{W}$-concept is extended to a sorption $M(n=6) M T$ phenomena in the bi-functional L-NanoComposites (NC).

d) Visual computerized sci. animations created show clearly the interference of the Xn-concentration waves for the paired 3,4p \& m1,2-principal components sorbed onto 6R0-nano-sites.

e) Computerized Visualized Simulation results show the interference of the principal peculiar $\{\mathrm{X} 1,2,6(\mathrm{~L}, \mathrm{~T})\}$-waves in the $\mathrm{NC}$ via the phenomenological wave (W)-concept.

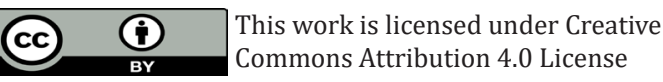

To Submit Your Article Click Here: Submit Article

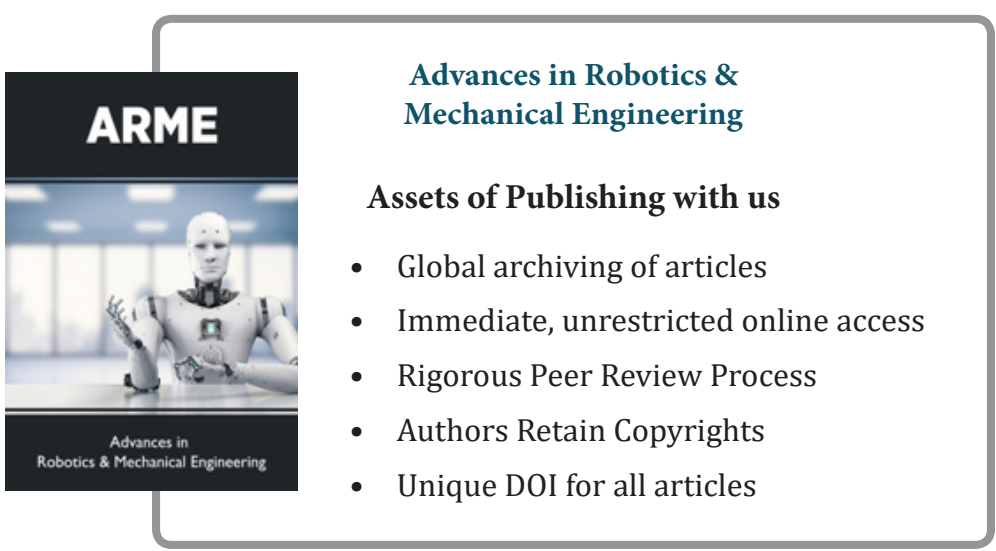

